\title{
Phobia-relevant illusory correlations: The role of phobic responsivity
}

Citation for published version (APA):

de Jong, P. J., \& Merckelbach, H. L. G. J. (2000). Phobia-relevant illusory correlations: The role of phobic responsivity. Journal of Abnormal Psychology, 109(4), 597-601. https://doi.org/10.1037/0021843X.109.4.597

Document status and date:

Published: 01/01/2000

DOI:

10.1037/0021-843X.109.4.597

Document Version:

Publisher's PDF, also known as Version of record

\section{Please check the document version of this publication:}

- A submitted manuscript is the version of the article upon submission and before peer-review. There can be important differences between the submitted version and the official published version of record.

People interested in the research are advised to contact the author for the final version of the publication, or visit the DOI to the publisher's website.

- The final author version and the galley proof are versions of the publication after peer review.

- The final published version features the final layout of the paper including the volume, issue and page numbers.

Link to publication

\footnotetext{
General rights rights.

- You may freely distribute the URL identifying the publication in the public portal. please follow below link for the End User Agreement:

www.umlib.nl/taverne-license

Take down policy

If you believe that this document breaches copyright please contact us at:

repository@maastrichtuniversity.nl

providing details and we will investigate your claim.
}

Copyright and moral rights for the publications made accessible in the public portal are retained by the authors and/or other copyright owners and it is a condition of accessing publications that users recognise and abide by the legal requirements associated with these

- Users may download and print one copy of any publication from the public portal for the purpose of private study or research.

- You may not further distribute the material or use it for any profit-making activity or commercial gain

If the publication is distributed under the terms of Article $25 \mathrm{fa}$ of the Dutch Copyright Act, indicated by the "Taverne" license above, 


\title{
Phobia-Relevant Illusory Correlations: The Role of Phobic Responsivity
}

\author{
Peter J. de Jong and Harald Merckelbach \\ Maastricht University
}

\begin{abstract}
The authors investigated the role of phobic responsivity in the generation of phobia-relevant illusory correlations. As a means of disentangling the contributions of prior fear and elicited fear responses, half of a group of phobic women received $1 \mathrm{mg}$ alprazolam $(n=21)$, and half received a placebo $(n=22)$. A group of nonfearful women $(n=24)$ was included to control for prior fear per se. Participants were exposed to slides of spiders, weapons, and flowers that were randomly paired with a shock, a siren, or nothing. Postexperimental covariation estimates and on-line outcome expectancies were assessed. Irrespective of botl prior and elicited fear, participants postexperimentally overassociated spiders and shock. Yet, only women with spider phobia displayed a persisting fear-confirming expectancy bias. This bias was similar for the placebo and alprazolam groups. Thus, the bias appeared to be due to preexisting phobogenic beliefs, whereas phobic responsivity played a negligible role.
\end{abstract}

A striking feature of phobic fear is its persistence in the absence of contingent aversive events. There is increasing evidence that Ceal-confirming cognitive biases play a role in this persistence (Willians, Watts, MacLeod, \& Mathews, 1997). Covariation bias is one of the eognitive biases that is assumed to play a role in the relricturiness of phobic fear. Germane to this, Tomarken, Mineka, and Cook (1989) showed that individuals high in fear systematically overestimate the contingency between pictures of their feared object and aversive outcomes. Recent studies have documented similar illusory correlations (ICs) in the context of other anxiety disorders such as panic disorder (Pauli, Montoya, \& Martz, 1996) and fear of llying (Pauli, Wiedemann, \& Montoya, 1998). Thus, jt appears that IC's represent a common characteristic that may play a role in a wide variety of anxiety disorders. This cognitive bias may have clinical significance in that it serves to inflate danger expectations and, consequently, maintain irrational fear. Accordingly. (residual) posttreatment IC has been found to be a powerful predictor of relapse after successful exposure treatment (de Jong, vin den Hout, \& Merckelbach, 1995).

By now, covariation bias is a well-documented phenomenon. Yet, its underlying mechanisms are still a matter of debate. Per-

Peter J. de Jong, Facully of Health Sciences, Department of Medical, Clinicul, and Experinental Psychology, Maastricht University, Maastricht, lle Netherlands; Farald Merckelbach, Faculty of Psychology, Department of Iixperimental Psycholugy, Maastricht University, Maastricht, the Netherlaticls.

We thank Tanja van den Hoogen for her assistance during the data necpuisition and scoring of the data and Annic Raven and Ina Leeuw for taking care of the organizational aspects of the "spider project," as well as for their contribution to the scoring of the physiological signals. In additin)., we are grateful to Arnoud Arntz for his useful advice during the preparation of this study, Merel Kindt and Marcel van den Hout for their useful comments on earlier versions of this article, and Erik Schouten for his statistical advice.

Correspondence concerning this article should be addressed to Peter J. de Jong, Department of Medieal, Clinical, and Experimental Psychology, Faculty of Health Sciences, Matastricht University, P.O. Box 616, 6200 MD Maastricht, the Netherlands. Electronic mail may be sent to P.xieJong@DEP.unimaas.nl. haps most important in this respect is the role of affective responsivity. There is evidence suggesting that similarity between affective responses to stimuli and outcomes is a prerequisite for fearrelevant ICs to occur (Tomarken, Sutton, \& Mineka, 1995). Yet, it remains unclear how affective similarities between (phobic) cues and (aversive) outcomes produce ICs. One explanation might be that affective similarities constitute particular expectancies about stimulus-outcome contingencies (Davey \& Dixon, 1996), which, in turn, may facilitate the generation of ICs. A second explanation might be that the impact of discrete cue-outcome pairings is potentiated whenever there is an affective similarity (i.e., match) between a particular stimulus and a particular outcome (cf. Lang, Bradley, \& Cuthbert, 1990). If the former is true, phobia-specific ICs can best be construed as a special case of the more general phenomenon that ICs arise in the presence of strong prior expectations and ambiguous situational information (Alloy \& Tabachnik, 1984). The latter pathway implies that emotional responses during confrontation with phobic situations play a crucial role in mediating ICs.

The issue of whether ICs derive from enduring phobogenic expectancies or from distortions induced by fear responses, or both, is not only of academic interest but may also have clinical implications. For example, if fear-confirming judgmental processes critically depend on emotional states that arise during exposure to phobic stimuli, this would imply that attempts to modify these maladaptive judgment errors are successful only when phobic individuals are in an anxious mood state. If not, the preexisting phobogenic beliefs seem to be the proper (cognitive) targets.

To shed some light on this issue, the present study was designed to test the hypothesis that phobic responsivity plays a crucial role in the development of phobia-specific ICs. As a means of manipulating participants' fear responses independently of their prior fear levels, half of a treatment-seeking group of spider-phobic women received a clinical dose $(1 \mathrm{mg})$ of alprazolam. We used alprazolam because it is a widely prescribed and fast-acting anxiolyticum (Ziekenfondsraad, 1998). There is abundant research showing that, in phobics, a single dose of $1 \mathrm{mg}$ results in a clinically significant reduction in self-reported anxiety and 
strength of symptoms (Wilhelm \& Roth, 1997), Similar results have been obtained with the related drug diazepam (Sartory, MacDonald, \& Gray, 1990; Whitehead, Blackwell, \& Robinson, 1978). To control for the role of prior fear per se, we also tested a group of nonfearful women. During the experiment, participants' skin conductance responses were measured as an index of phobic responsivity.

To index covariation bias, we assessed both postexperimental covariation estimates and on-line outcome expectancies (de Jong, Merckelbach, \& Arntz, 1995). Such a procedure allows one to follow the pattern of expectancies over trials and to examine the influence of prior fear and elicited fear on the rate of disconfirmation of participants' expectancies.

\section{Method}

\section{Participants}

Participants were 43 women with spider phobia who applied for treatment $(M$ age $=28.9$ years, range $=17-55$ ) and 24 women without a fear of spiders $(M$ age $=30$ years, range $=20-40)$. Mean educutional levels were 6.6 (range $=2-9$ ) for the phobic group and 6.7 (range $=2-9$ ) for the nomphobic group on an 11-point scale anging from no education finished (1) to university education (11). Alter a telephone interview, applicants completed the Spider Phobia Questionnaire (SPQ; Klorman, Weerts, Hastings, Melamed, \& Lang, 1974) and the Symptom Check List (Arrindell \& Ettema, 1986). Participants were also asked to describe to what extent theit fear interfered with their daily lives. Only individeals who had SPQ scores above 16 (cf. Arntz \& Lavy, 1993) and who indicated that their phobia strongly interfered with daily life were included. To avoid comorbidity confounds, we excluded individuals with "above average" scores on any subscale of the Symptom Check List. The same criteria were used for the control group. Members of this group were rectuited through newspaper advertisements and were paid for their participation. Mean SPQ scores were 23.4 (range $=17-29$ ) for the phobic group and 2.6 (range $=0-8$ ) for the control group.

\section{Apparatus and Stimulus Materials}

We used four slides of spiders, four of flowers, and four of weapons. There were three types of outcomes: a 1-s shock, a $1-s$ siren, or nothing. Electrical shocks were administered to participants' lateral side of the upper right arm via two $\mathrm{Ag} / \mathrm{AgCl}$ electrodes $(8 \mathrm{~mm})$. A pointer lever was used to metsure outcome expectancies. Skin conductance responses were measured with a Picker Schwartzer colpler (EDA 48) connected to two $\mathrm{Ag} / \mathrm{AgCl}$ electrodes $(8 \mathrm{~mm})$ that were filled with isotonic paste and attached to the medial phalanges of the third and fourth fingers. A $486 \mathrm{PC}$ sampled the signals at $1000 \mathrm{~Hz}$. Another PC controlled sampling of the signals and stimulus presentations. All women in the phobic group received $\mathfrak{n}$ capsule containing $1 \mathrm{mg}$ alprazolam or inert material. Alprazolam and placebo were administered according to a double-blind procedure. Participants signed an informed consent form before entering the study, which was approved by the standing Ethics Review Committee of Maastricht University,

After a single 1-ing oral dose of alprazolam, peak plasma concentrations occur in about $45 \mathrm{~min}$ (Greenblatt \& Wright, 1993). Because the elimination half-life of alprazolam exceeds $9 \mathrm{hr}$, therapeutic concentrations were likely to be present during the entire experiment. In a subsequent experiment (not reported here), it was necessary for half of the placebo and half of the alprazolam capsules to contain $50 \mathrm{mg}$ naltrexone. There are no a priori reasons to suspect that naltrexone had any pharmacological effect in the present experiment, because it is very unlikely that endogenous opioids are released during relatively mild and controllable stressors of the sort used here (Curtis \& Glitz, 1988; Janssen \& Arntz, 1997). Accordingly, preliminary analyses confirmed the absence of significant effects of naltrexone witl respect to the relevant comparisons.

\section{Procedure}

Phobic women were randomly assigned to the placebo $(n=22)$ or alprazolam $(n=21)$ group. SPQ scores were similar for the two groups (placebo group, $M=23.4$; alprazolam group, $M=23.3$ ). After $1 \mathrm{hr}$, electrodes were attached, and shock intensity level was determined via a shock work-up procedure. Shock level was increased in steps of $0.2 \mathrm{~mA}$ until the participant indicated that the shock was definitely uncomfortable but not painful. The mean stimulation levels that were reached were 5.5 $\mathrm{mA}$ for the alprazolam group and $4.3 \mathrm{~mA}$ for the placebo group. For the nonphobic control group, the mean level was $3.1 \mathrm{~mA}$. Participants were instructed to indicate outcome expectancies during each slide presentation by means of a pointer (left $=$ siren, right $=$ shock, middle $=$ nothing).

Participants were exposed to 72 slides (8-s duration). Af slide offset, one of the three possible outcomes occurred. The conditional probability of any outcome given the prior occurrence of each category of slide was .33, and so was the probability of occurrence of each slide type and each type of outcome. Intertrial intervals ranged from $10 \mathrm{~s}$ to $30 \mathrm{~s}$. At the end of the experiment, participants were asked to estimate the occurrence of ench outcome given the prior occurrence of each slide type. For these covariation estimates, we used $100-\mathrm{mm}$ visual analogue scales ranging from $0 \%$ to $100 \%$. For ench outcome, the three pertinent scales were presented on the same sheet, Scale order was fixed.

\section{Results}

\section{Skin Conductance Response}

A response was defined as the maximal continuous deflection in conductance starting in the $1-4-\mathrm{s}$ interval after slide onset (fitst interval response [FIR]). Before the analyses, electrodermal responses (magnitudes) were normalized by means of a square-root transformation. A one-way (nonphobic vs, placebo vs, alprazolam) analysis of variance (ANOVA) revealed a significant effect of group, $F(2,60)=5.6, p<.01, \eta^{2}=17$. Bonferroni post hoe tests indicated that mean FIRs on spider trials were smaller for nonphobic than for phobic participants who received a placebo $(p=$ $\left..007, \eta^{2}=.21\right)$, means being $.32(S D=.21)$ and $.55(S D=.24)$, respectively. (Units were measured in square roots of microsiemens.) In line with its anxiolytic properties, phobic women who received alprazolam displayed smaller FIRs on spider trials than the placebo group $\left(p=.05, \eta^{2}=.13\right]$, means being $.38(S D=$ $.21)$ and $.55(S D=.24)$, respectively. Mean FIRs of the alprazolam group were similar to those of the nonphobic participunts $\left(p=1.0, \eta^{2}=.02\right]$.

\section{Postexperimental IC}

We used a summary measure of the postexperimental IC for the target stimuli (cf. Tomarken et al., 1995). This bias index was calculated for each participant according to the following formula: $P$ (shock/spicler) $-[P$ (siren/spider) $+P$ (nothing/spider $)] / 2-$ $\{P$ (shock/flower $)-[P$ (siren/flower $)+P$ (nothing/flower $)] / 2+$ $P($ shock/weapon $)-[P($ siren/weapon $)+P$ (nothing/weapon $)] / 2\} /$ 2. Mean bias indexes are shown in Table 1 as a function of group. A one-way ANOVA revealed that the intercept was significantly larger than zero, $F(1,64)=41.5, p<.001, \eta^{2}=.40$, indicating that, in general, participants displayed a covariation bias between 
Table 1

Mean Estimutes of Contingency and Bias Measures for the Nonphobic Control Group $(n=24)$ and for the Phobic Women Who Received a Placebo $(n=22)$ or Alprazolam $(n=21)$

\begin{tabular}{|c|c|c|c|c|c|c|c|c|c|c|}
\hline \multirow[b]{2}{*}{ Condition } & \multicolumn{3}{|c|}{ Spicler } & \multicolumn{3}{|c|}{ Weapon } & \multicolumn{3}{|c|}{ Flower } & \multirow{2}{*}{$\begin{array}{l}\text { Bias } \\
\text { index }\end{array}$} \\
\hline & Shock & Siren & Nothing & Shock & Siren & Nothing & Shock & Siren & Nothing & \\
\hline \multicolumn{11}{|l|}{ Control } \\
\hline$M$ & $53 .()$ & 37.8 & 27.0 & 42.7 & 43.1 & 30.3 & 37.8 & 36.5 & 43.5 & 18.7 \\
\hline$s D$ & 22.3 & 19.5 & 20.5 & 23.1 & 23.3 & 20.6 & 25.9 & 19.9 & 19.1 & 39.7 \\
\hline \multicolumn{11}{|l|}{ I'lacebo } \\
\hline $\begin{array}{l}M \\
S O\end{array}$ & $\begin{array}{l}3.3 .7 \\
21.3\end{array}$ & $\begin{array}{l}36.1 \\
28.7\end{array}$ & 40.3 & 39.3 & 43.9 & 38.9 & 28.1 & 35.8 & 60.3 & 26.4 \\
\hline \multicolumn{11}{|l|}{ Alprazolam } \\
\hline$M$ & 56.6 & 35.9 & 28.7 & 31.5 & 45.7 & 29.6 & 26.4 & 38.0 & 46.3 & 35.5 \\
\hline$S D$ & 22.5 & 20.6 & 20.7 & 18.2 & 21.7 & 22.3 & 19.2 & 13.0 & 28.7 & 34.3 \\
\hline
\end{tabular}

spiclers and shock. The magnitude of the covariation bias was found to be independent of group, $F(2,64)=1.6, p=.21, \eta^{2}=$ .05 .

\section{On-Line Outcome Expectancies}

For each type of slicte, the number of trials on which participants indicated expecting al shock outcome was computed. This was done for each of the six trial blocks (each block containing four (rials). Lixpectancies on spider trials were compared with those on the pooled llower-weapon trials (cf. de Jong, Merckelbach, \& Arntz, 1095). Multivariate analysis indicated that, in general, participants displiyed relatively strong shock expectancies after spider slides, $f(1,64)=37.1, p<.001, \eta^{2}=.37$. Yet, the three groulys significantly differed with respect to the strength of this expectancy bias, $f(2,64)=6.9, p<.00 !, \eta^{2}=.18$ (see Figure 1 ). No dilfurences energed with respect to the linear trends of the stimulus caltegories hetween groups, $F(2,64)=1.1, \eta^{2}=.04$.

Bonferroni post hoc tests indicated that the proportion of trials on which a shock was expected atter spider slides relative to that alter pooled l'lower and weapon slides was significantly larger for the placebo group than for the eontrol group $\left(p=.03, \eta^{2}=.14\right)$. Also, the alprazolam group displayed relatively strong shock expectancics after spider slides compared with the no-fear control group $\left(p=.002, \eta^{2}=.23\right)$. No difference emerged between the placebo group and the alprazolam group in this respect $(p=1.0$, $\left.\eta^{2}=.02\right)$

\section{Discussion}

The level of phobic arousal elicited on spider trials was significantly smaller in the alprazolam group than in the placebo group. In fact, FIRs to spider slides in the alprazolam group were of a magnitude similar to those in the nonphobic group. Thus, our phatmacological intervention to manipulate phobic responsivity irrespective of prior fear appeared successful. Clearly, this pattern of findings speaks to the anxiolytic status of alprazolam. Meanwhile, it should be acknowledged that, in the present study, anxiety was not assessed with subjective mensures. Therefore, the present data do not rule out the remote possibility that alprazolam was ineffective in reducing the impact of the spider slides at the subjective level.

\section{Postexperimental IC}

In line with previous studies, the placebo group reported a convincing postexperimental IC. Unexpectedly, however, the nonfearful control participants displayed a very similar IC. It is important to note that the lack of differences between the placebo and the nonfearful control group was due not to a weak IC in the placebo group but, rather, to a strong IC in the control participants. This pattern of findings refutes the assumption that prior fear is a necessary prerequisite for the occurrence of robust phobia-relevant ICs. Moreover, it implies that on-line elicited fear is not a crucial factor in the generation of ICs. Consistent with this, there was no difference between the alprazolam and the placebo group with respect to the postexperimental IC.

The absence of a phobia-specific postexperimental IC in the present study is difficult to reconcile with our previous finding that treatment attenuates postexperimental ICs in individuals with spider phobia (de Jong, Merckelbach, Arntz, \& Nijman, 1992). One explanation might be that treatment introduced a bias against an association of spiders and shock. In line with this, a subsequent study revealed that only a minority of treated women indicated expectation of a shock after the first spider slide (de Jong, Merckelbach, \& Arntz, 1995).

The lack of prior fear effects also contrasts with IC studies relying on analogue groups. These studies typically have shown that individuals high in fear exhibit a relatively strong postexperimental IC between spiders and shock (e.g., Tomarken et al., 1989). On the other hand, our failure to document prior fear effects accords well with recent findings indicating that ICs concerning blood-injury stimuli (Pury \& Mineka, 1997) and angry faces (de Jong, Merckelbach, Bögels, \& Kindt, 1998) are not affected by prior fear. Apparently, postexperimental ICs may be affected by prior fear, but they seem sensitive as well to other factors that are as yet unknown. These may be related to stimulus characteristics, sample differences, demand, or level of education. The vulnerability for such inadvertent influences is likely to be stronger for postexperimental ICs than for on-line reported outcome expectancies because the covariation rating task from which ICs are derived is intrinsically more abstract and difficult than the on-line task (cf. Amin \& Lovibond, 1997). Moreover, postexperimental ICs are likely to be relatively unreliable because they reflect a single measurement rather than a repeated assessment, as is the case for 


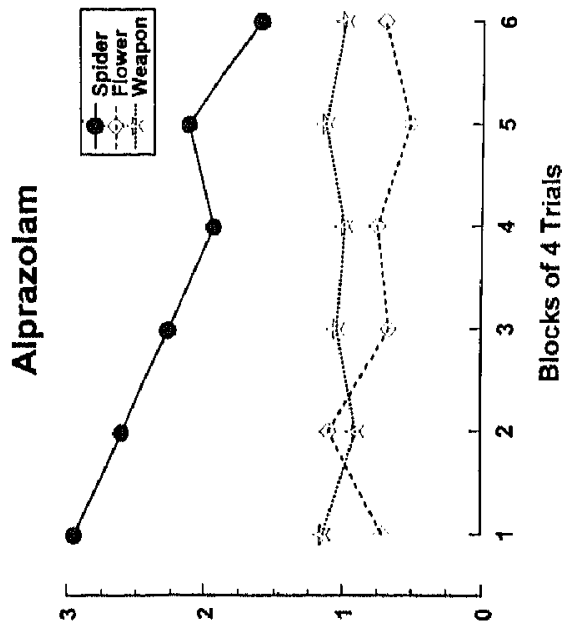

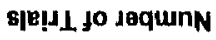

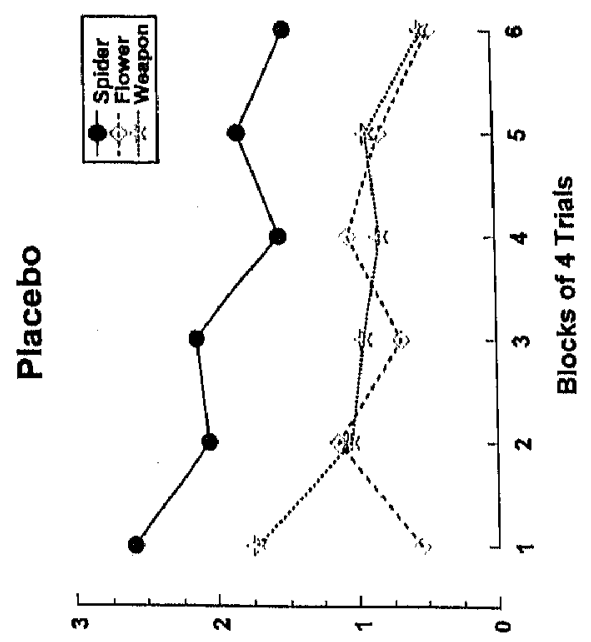

8|e! 1 jo JoqunN

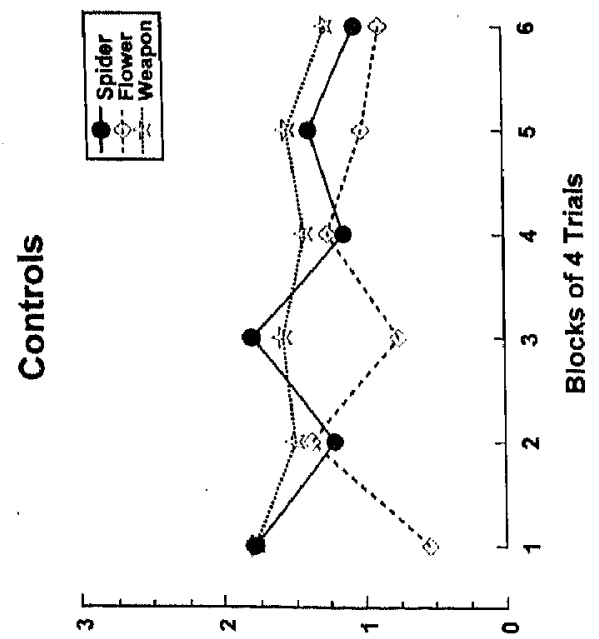

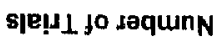

on-line expectancies. Meanwhile, from a theoretical stance, the inconsistent findings with respect to the influence of prior fear on IC are uncomfortable, because they cast doubt on the validity of the postexperimental IC.

\section{On-Line Expectancies}

In contrast to the postexperimental IC, the on-line outcome expectancies were strongly affected by prior fear: The spiderphobic women displayed a more persistent phobia-relevant expectancy bias than the nonphobic control women. Yet, no evidence was found to suggest that the insensitivity to disconfirming experiences critically depended on phobic responsivity. That is, the biased expectancies were similar for the alprazolam and placebo groups. If anything, the expectancy bias was even stronger in the alprazolam group than in the placebo group. Thus, the absence of a difference between the groups seems not to be attributable to a power problem (e.g., relatively small sample or modest anxiolytic activity of alprazolam). All in all, it appears that phobia-induced prior beliefs rather than potentiated phobic responsivity were responsible for the persisting expectancy bias.

Some comments are in order with respect to the dissociation between on-line expectancies and the postexperimental IC. Although some studies have provided evidence of a positive association between on-line expectancies and postexperimental IC (de Jong, Merckelbach, \& Arntz, 1995; de Jong et al., 1998), the present study adds to the evidence that postexperimental ICs are not simply a continuation of on-line expectancy biases. That is, several experiments have shown that post-experimental ICs can be found even if on-line expectancy biases have already disappeared at the end of the experiment (e.g., Amin \& Lovibond, 1997). One explanation for this might be that, although participants have gradually learned to correct their prior expectancies during the experiment, their memory may nevertheless have incorporated the biased expectancies that were evident at the beginning of the experiment (Amin \& Lovibond, 1997).

In conclusion, the present data indicate that phobic responsivity to phobia-relevant cues is not a crucial factor in the generation of postexperimental ICs. In addition, our results strongly suggest that prior beliefs, rather than elicited phobic arousal, play a dominaut role in phobia-relevant expectancy bias. Therefore, our findings seem to indicate that the appropriate target for modifying these maladaptive judgment errors would be preexisting phobogenic beliefs rather than the tendency to process events on-line in such a way as to exaggerate threat.

\section{References}

Alloy, L. B., \& Tabachnik, N. (1984). Assessment of covariation in humans and animals: The joint influence of prior expectancies and current situational information. Psychological Review, 91, 112-149.

Amin, J. M., \& Lovibond, P. F. (1997). Dissociations between covariation bias and expectancy bias for fear-relevant stimuli, Cognition and Emo. tion, 11, 273-289.

Aintz, A., \& Lavy, E. (1993). Does stimulus elaboration potentiate exposure in vivo treatment? Two forms of one-session treatment of spicle phobia, Behcivioural Psychotherapy, 21, 1-12.

Arrindell, W. A., \& Ettema, J. H. M. (1986). Dutch transtation and adaptation of the SCL-90. Lisse, the Netherlands: Swets \& Zeitlinger. 
Curtis, G. C., \& Glitz, D. A. (1988). Neuroendocrine findings in anxiety disonders. Endocrinology of Neuropsychiatric Disorders, 17, 131-147.

Davey, G. C. L., \& Dixon, A. L. (1996). The expectancy bias model of selective associations: The relationship of judgments of CS dangerousness, CS-UCS similarity and prior fear to a priori and a posteriori covariation assessments. Behaviour Research and Therapy, 34, 235252.

de Jong, P. J., Merckelbach, H., \& Arntz, A. (1995). Covariation bias in phobic women: The relationship between a priori expectancy, on-line expectancy, autonomic responding, and a posteriori contingency judgment. Journal of Abnomal Psychology, 104, 55-62.

de Jong, P. J., Merckelbach, H., Arntz, A., \& Nijman, H. (1992). Covariation delection in treated and untreated spider phobics. Joumal of $A b$ nomal Psychology, 101, 724-727.

de Jong, P. J., Merckelbach, H., Bögels, S., \& Kindt, M. (1998). Illusory correlation and social anxiety. Behaviour Research and Therapy, 36. 1063-1073.

de Jong, P. J., van den Hout, M. A., \& Merckelbach, H. (1995). Covariation bias and the return of fear. Behaviour Research and Therapy, 33, 211-213.

Greenblatt, D. J., \& Wright, C. E. (1993). Clinical pharmacokinetics of alplazolam: Therapeutic implications. Clinical Phamacokinetics, 24, $453-471$.

Janssen, S. A., \& Aintz, A. (1997), No evidence for opioid-mediated analgesia induced by phobic fear. Behaviour Research and Therapy, 35, $823-830$

Klorman, R, Weerts, T. C., Hastings, J. E., Melamed, B. G., \& Lang, P. J. (1974). Psychometric clescription of some specific fear questionnaires. Beharior Therapy, 5, 401-409.

Lang, P. J., Bradley, M. M., \& Cuthbert, B. N. (1990). Emotion, attention, and the startle reflex. Psychological Review, 97, 377-395.

Pauli, P., Montoya, P., \& Martz, G.-E. (1996), Covariation bias in panicprone individuals. Jommal of Abnormal Psychology, 105, 658-662.
Pauli, P., Wiedemann, G., \& Montoya, P. (1998). Covariation bias in flight phobics, Jounal of Anxiety Disorders, 12, 555-565.

Pury, C. L. S., \& Mineka, S. (1997). Covariation bias for blood-injury stimuli and aversive outcomes. Behaviour Research and Therapy, 35 , $35-47$.

Sartory, G., MacDonald, R., \& Gray, J. A. (1990). Effects of diazepam on approach, self-reported fear and psychophysiological responses in snake phobics. Behaviour Research and Therapy, 28, 273-282.

Tomarken, A. J., Mineka, S., \& Cook, M. (1989). Fear-relevant selective associations and covariation bias. Joumal of Abnomal Psychology, 98 , $381-394$

Tomarken, A. J., Sutton, S. K., \& Mineka, S. (1995). Fear-relevant illusory correlations: What types of associations promote judgmental bias? Jour nal of Abnomal Psychology, 104, 312-326.

Whitehead, W. E., Blackwell, B., \& Robinson; A. (1978). Effects of diazepam on phobic avoidance behavior and phobic anxiety. Biological Psychiatry, 13, 59-64.

Wilhelm, F, H., \& Roth, W. T. (1997). Acute and delayed effects of alprnzolam on flight plobics during exposure. Behaviour Research and Therapy, 35, 831-841.

Williams, J. M. G., Watts, F. N., MacLeod, C., \& Mathews, A. (1997), Cognitive psychology and emotional disorders. Chichester, England: Wiley.

Ziekenfondsraad. (1998). Farmacotherapeutisch Kompas: medisch farmaceutische uitgave van de Centrale Medische Pharnacentische Commissie van de Ziekenfondsraad [Pharmacotherapeutic compass: Medical pharmacentic release of the Central Medical Pharmaceutic Committee of the National Council of Health Service]. Amstelveen, the Netherlands: Author.

Received April 14, 1999

Revision received September 24, 1999

Accepted January 20, 2000 